Linguagem em (Dis)curso - LemD, v. 9, n. 1, p. 181-185, jan./abr. 2009

\title{
RESENHA DE "DISCURSO POLÍTICO” [CHARAUDEAU, P. - SÃO PAULO: CONTEXTO, 2006]
}

Jaçanã Ribeiro*

O livro de Patrick Charaudeau, professor de Ciências da Linguagem na Universidade de Paris XII e diretor do Centro de Análise do Discurso, apresenta uma reflexão sobre a natureza, funções, regras e procedimentos do discurso político enquanto processo de influência social $^{1}$. A obra traz também um questionamento importante sobre $\mathrm{o}$ processo contemporâneo de construção de identidades (instâncias do contrato de comunicação do discurso político) e um diagnóstico prudente sobre a influência da mídia na emergência de uma nova ética política. Marcada pelo signo da retórica, a análise incide sobre as condições e estratégias de persuasão na constituição de identidades que só se mostram enquanto máscaras: a ordem da verossimilhança e do possível como fundamentais para o "viver em comunidade" político.

$\mathrm{Na}$ primeira parte do livro o autor procura definir a natureza do discurso político, que tem como fundamento a imbricação entre linguagem e ação. A palavra política funciona entre uma verdade do dizer e uma verdade do fazer: uma verdade da ação que se manifesta através de uma palavra de decisão, e uma verdade da discussão que se manifesta através de uma palavra de persuasão (razão) ou sedução (paixão). $\mathrm{O}$ autor diferencia sua abordagem daquelas de Weber, Arendt e Habermas, sustentando um duplo fundamento do discurso político (p. 45-46): esse resulta de uma mistura entre a palavra que deve fundar o político (como idealidade dos fins) e aquela que deve gerar a política (enquanto prática). Para Charaudeau, o discurso político funciona na conjunção de discursos

\footnotetext{
* Doutorando no Programa de Pós-Graduação em Linguística da Universidade Federal de Santa Catarina. E-mail: <novoepicuro@yahoo.com.br>.

${ }^{1}$ Entre os interesses do autor estão o discurso de informação (CHARAUDEAU, 2006) e o talk-show televisivo (CHARAUDEAU, 2000), entre outros.
} 


\section{2}

de idéias e discursos de poder (verdade e possibilidade), pensamento e ação. Uma vez que os primeiros dizem respeito à verdade, e os segundos à problemática do verdadeiro, do falso e do possível, desde o início a questão central do livro se coloca em termos retóricos: dada essa duplicidade, o discurso político teria tendência a se orientar do logos em direção ao ethos e ao pathos (conteúdo e encenação)?

$\mathrm{Na}$ segunda parte da obra, Patrick Charaudeau descreve a estrutura do teatro político e as estratégias dos seus atores (a metáfora do teatro é retomada ao longo do todo livro). As instâncias de comunicação (política, cidadã e mediática) são definidas por sua finalidade comunicacional, por exemplo, propor, reivindicar, denunciar, etc. Dada a relevância do afeto na persuasão, um ponto importante na sua constituição é o espaço do mentir verdadeiro como estratégia de sedução ( $A$ mentira na cena pública):"todo político sabe que lhe é impossível dizer tudo, a todo momento, e dizer as coisas exatamente como ele as pensa ou concebe, pois suas palavras não devem atrapalhar sua ação" (p. 104-105). $\mathrm{O}$ autor esclarece assim que, no contrato de comunicação político, os atores da instância política devem sempre obedecer à lógica do parecer verdadeiro, empregando para esse fim estratégias para evitar "ter mentido", entre elas a generalidade, o silêncio, a omissão e a denegação. O caso é que sem essa verdade de aparências não haveria ação política possível.

A terceira parte, que trata das imagens dos atores políticos, toma emprestado da retórica um dos termos chave da análise de Charaudeau, o ethos como construção da imagem de si. Uma novidade aqui é o fato de o autor trazer para a cena a pessoa do locutor, bem como a própria massa de seu corpo como fonte de identificação ("ethos de potência", por exemplo). Uma semiótica multimodal do ethos inclui ainda a vocalidade enquanto procedimento expressivo que atua na construção da imagem de si (falar forte, tranquilo, falar bem). Não ficam claros os critérios de definição das vocalidades, sendo tais valores significados sem significantes definidos. Entretanto, é importante ressaltar que as qualidades do ethos são ambivalentes, dependendo das circunstâncias. A questão de peso levantada no final da terceira parte retoma as noções da retórica para direcionar o balanço final da obra: como interpretar a deriva do discurso político? Nesse sentido, ele também coloca as sequintes questões: $\mathrm{O}$ ethos tem função de ocultação do logos através de 
uma falsa evidência que não se discute? Entre logos, pathos e ethos, qual domina, qual oculta os outros, qual transmite evidência?

A quarta parte apresenta uma importante revisão terminológica que distingue teorias, doutrinas, ideologias, para elaborar outra noção chave da análise que é a de imaginário sociodiscursivo. Esse é definido como um "universo de significação que funda a identidade de um grupo" (p. 202-204). Fontes de identificação e de estratégias de persuasão, os imaginários discursivos são imaginários de verdade, materializados discursivamente em textos, provérbios, máximas que devem ser compreendidos por um maior numero possível de interlocutores, dada a condição midiática do contrato de comunicação. Mantendo a perspectiva retórica, a verdade dos imaginários é definida em termos de adesão, dependente de seu efeito e força. $\mathrm{Na}$ sequência, o autor apresenta os principais imaginários de verdade, todos eles tendo por comum a referência a valores do bem em comunidade: imaginários de "tradição", de "modernidade", de "sobernania".

O final do livro apresenta um balanço que pretende se contrapor à idéia de uma degenerescência do político, avançando outra interpretação do estatuto da máscara, do ethos e do pathos em detrimento do logos no discurso político. Retomando seu estudo sobre a influência das mídias, a questão é a de saber se outro contrato é possível ou se o discurso político está condenado a se diluir no mediático. O único espaço que parece restar para o logos nesse discurso é o das discussões de especialistas das quais os políticos estão ausentes:

[...] os políticos, nesse mundo moderno da encenação e do espetáculo, se quiserem exercer alguma influência sobre os cidadãos, devem aprender as novas regras de insinceridade e do mentir verdadeiro legítimos, aceitar esse paradoxo moderno segundo o qual se dá uma grande importância ao parecer justamente numa época em que a cidadania é mais esclarecida. (p. 305-306)

A hipótese da degenerescência se baseia na constatação da construção da imagem política através da sedução, dramatização dos acontecimentos, uma visão do mundo fragmentada e atemporal e uma série de derrapagens do discurso mediático, como, por exemplo, de veja sobre o que se deve pensar para veja o que se deve pensar, ou de veja o que dizem os 


\section{4}

politicos para veja o que eles pensam de verdade (p. 293). Entretanto, para se contrapor a essa hipótese, que como Charadeau afirma acertadamente, favorece o populismo ${ }^{2}$, o autor nos apresenta não uma constatação de uma nova ética, mas uma vontade de uma nova via, decorrente de seu diagnóstico detalhado. Trata-se de uma crença em uma nova relação entre as instâncias política e cidadã, na qual a máscara é assumida como tal: nova relação entre o político (fundamento das idealidades) e a política (prática de ajustamento às idealidades), onde a ética política seja baseada em um ethos de exemplaridade, na relação de confiança entre instâncias, na escuta entre mandatários e eleitores. Segundo Charaudeau, a instância política e a mediática deveriam ter a coragem de fazer a instância cidadã compreender que não pode tudo saber, que o segredo e a maquilagem da verdade fazem parte do jogo de máscaras do discurso político. Essa nova ética política se apresenta como fundamentalmente retórica, no sentido moderno $^{3}$ segundo o qual o pathos e o ethos são assumidos enquanto componentes do ato de linguagem político, mas com a intenção de não confundir a máscara com a mentira; de um demagógico: "eu vos digo tudo, não vos escondo nada", um novo contrato entre a instância política e mediática deveria privilegiar o necessário: "não vos digo tudo, mas ai está o que posso vos dizer". Resta saber se há possibilidade desse contrato na lógica dramática de agressores e vítimas do discurso midiático.

E assim como a midiatização impõe novos contornos à forma da retórica, são os próprios conceitos de imaginário-sociodiscursivo e de ethos dele decorrente que impõem uma relativização na passagem da versão francesa do livro para a realidade brasileira. De fato, a maioria dos conceitos deve passar por atento exame na confrontação com nosso modo de fazer política, pois embora alguns imaginários sustentem a base do pensamento democrático, não se devem desprezar novas formas de

\footnotetext{
${ }^{2}$ Os exemplos de degenerescência abundam e resistem ao argumento do autor. Na França, a última notícia política sobre Sarkozy é sua derrota judicial quanto ao seu pedido de interdição de comercializar um boneco voodoo com sua imagem. Os juízes privilegiaram o argumento de liberdade de expressão e não entenderam que o boneco, embora seja um ataque ao ethos político de Sarkozy, não chega ser um comércio de sua imagem pessoal, ao qual qualquer individuo tem o direito de se opor. No Brasil, para citar apenas um caso recente, como ver a exploração midiática da "sugestão" da propaganda de Marta Suplicy sobre a sexualidade de Kassab como a emergência de uma nova ética mais sã?

${ }^{3}$ Sentido que têm privilegiado autores como Reboul (1991), Meyer (1991), Guinzburg (2000), entre outros.
}

RIBEIRO - Resenha... 
construção da imagem de si como respostas às demandas locais de um auditório especificado. Aliás, mesmo no âmbito francês já existem trabalhos chamando a atenção para a mudança da retórica em Sarkozy: seu estilo mais de advogado do que de ex-aluno da ENA teria mais eficácia do que o falar forte, tranquilo, falar bem de seus antecessores.

\section{REFERÊNCIAS}

CHARAUDEAU, P. Discurso das mídias. São Paulo: Contexto, 2006.

A palavra confiscada. Lisboa: Instituto Piaget, 2000.

GUINZBURG, C. Rapports de force: histoire, rhétorique, preuve. Paris:

Gallimard, 2000.

MEYER, M. Le philosophe et les passions. Paris: P.U.F., 1991.

REBOUL, O. Introduction à la rhétorique. Paris: P.U.F., 1991.

Recebido em 30/10/08. Aprovado em 17/12/08. 